\title{
Investigator's Psychology and Its Role in Questioning the Defendant and the Witness
}

\begin{abstract}
Aleks Prifti
Doi:10.5901/ajis.2014.v3n4p233

\section{Abstract}

Throug this work we are tried to present e short expose of the methods and ways of frauds happened after 2000 in Albania. The analyse of these fraud pennal acts in this period has spotted into the focus the way of realization of the authors, being them professionals or simple perpetretors in that activity. What attracks most the attention in the study of this problem is the intesification of this criminal phenomenon in this period of econimical,political and social transition in these last 10 years in Albania and especially the sofistication of the ways,methods and means used by the envolved subjects in this criminal activity.A special space in this work is given tothe sinthesis of the elements of fraud carried out through the falsification of the official documents, aiming to steal the privateand public property. In all the notted cases in the investigative and criminalistic practice compaund elements of "Modus Operandi" of the profesionsit authors in different frauds, have been analized apart for each case and at the same time is done the matching of the elements dealing to the way of the repeated author. Another peculiarity of this work is that this natyre of crime strengthen the conviction that the repeated authors create a solid and dynamic stereotype which is conected to the place,time, way of beahviour,means and methods used for the realisation of the criminal goal etc. The work does not remain only to the theoreticla treatment of this criminal phenomenon but simultaneously it analyses concret cases and mainly those cases being investigated from the Economical Crime Department of Tirana Regional Police Directorate..
\end{abstract}

Keywords: Investigator, investigator's psychology, investigation, indictment, professionalism, scientific evidence, legal documentation.

\section{Introduction}

It is known that the activity, in a certain domain on a long term, develops habits, professional skills and abilities putting the professional print on it. For example, the job of economist develops to it precision and meticulosity. The job of actor, for example, by the need of repeated transformations, intense feelings, periodic contact with the public in various scenarios, brings him to a high level of sensitivity and knowledge creating a special state of mind to the audience through his capacity of understanding their reactions and to adapt depending on them. The doctor, in emergency cases, must act with calm in order to make a firm and sure decision and to make a diagnostic as accurate as possible. The painter perceives the nature more accurate than any other person through the colours and details of nature.

Without any doubt, the process of investigation puts its professional imprint on the investigator's psychology and develops his abilities, skills, interest and even other features, which shape the profile of a forensic investigator. The investigator is different from any other specialist, firstly because he is faced daily, with a lot of scenarios, people with different personalities, activities, and the reasons of these activities, their consequences and their causes. The investigator is obliged to focus, relatively with ease and fastness in many situations and problems, focusing on them, analyze them deeply and objectively. The facts above mentioned allow the investigator to fast develop his skills within this main link and, based on them, to manage to discover the course of actions. This develops in him, the observation capacity, and intuition, attention to details, a good memory, logical thinking and analysis. Overview on the investigator's psychology

In the forensics doctrine it is mentioned: "the investigator must adapt, understand the environment where the murder took place, understand and recreate, approximately, the route followed by the murderer to reach the victim, understand the reasons that determined the author of the criminal deed. For this thing it is necessary a developed intellectual capacity. It is not enough if the investigator establishes with approximation the circumstance of the murder. All these must be assessed based on an imaginary scheme and then, through a series of steps and practical actions is verified if the action took place in that way. He must know to control every step in order not to deviate from the established route and no to mistake the direction of the investigation, thing which could easily happen, when the author of the murder understands the weaknesses of the investigator and wants to lead the investigation in his interest" (Vishinski, 1956, p.348).

However, besides these positive things which he earned due to his profession, there are situations where this profession leaves other professional features in the psychology of certain investigators. Among them we can mention, for 
example, the doubt, sometimes sharpened, in the subjective understanding of certain situations, if taken as evidence. The problem resides in the fact that the investigator's psychology is sometimes subjective and makes him, unconscious; to sometimes accept other situations than the ones that are justified.

An experienced and conscious investigator never forgets this psychological moment and self-controls, having a critical attitude on intuition, deduction, impressions and assumptions. Self-control has an important role in the work of the investigator on the control of the scenarios proposed by him. In a close connection with the investigator's psychology it is the capacity to choose the correct scenario right from the beginning of the investigation, detailed control of it which establish is this scenario is plausible or not.

In practice, sometimes happens that less experienced investigators who choose from the beginning of the investigator a certain scenario, which they consider to be the correct one, subsequently without realizing, may fall under that scenario becoming its followers. In this case the investigator, without understanding this self-hypnotize, performs the investigation unilaterally, accepting with overzealous and without analyzing all the deeds and the circumstances which form the scenario and go further from the deeds and circumstances that belie this scenario or overlooks certain contradictions and gaps from the scenario built by him. Being blinded by the scenario chosen at the beginning of the investigation, the investigator regards the case subjectively without taking into consideration other scenarios and looses the professional clarity and accuracy.

\section{Investigator's Psychology in the Interrogation of the Defendant}

Eventually, the actions and the behaviour of the defendant, seen only through the accusations brought, become incriminating evidence, without actually being such evidence. In case of an unilateral approach, the most insignificant deed immediately becomes a deed with "serious" consequences, which is not in reality, lack of interest leads to an intentional and criminal omission, the word said pointlessly deviates from the purpose. To this it adds the surprisingly coincidence of the circumstance of the case, frequently met in the investigation, where, the defendant is cornered and does not understand what is happening to him and you shall understand clearly that for solving the case the investigator must be tenacious, conscious and objective.

There are cases where the unknown and tangled aspects of the deeds, details and reports get complicated, case where the less experienced investigator who encounters them, resigns. Intuition, talent, professional tenacity and objectivity of the investigator are features which guide him and help him solve the case and find out the truth. In these cases, the investigator sometimes must not only surmount the complicated situations of the causal, circumstances and incriminating evidence, but also the professional instinct to choose the scenario which seems to be the easiest and apparently the safest. In these cases, it is sometimes harder to prove the innocence of the defendant, who is in fact innocent and easier for the investigator, to irresponsibly connect the total of the non-objective evidence and under the weight of the "incriminating evidence", and to formulate at random the conclusion of the investigation and the accusations. In certain cases, the investigator must get over the insecurity habit, which he earned through his work as investigator, where he had to fight several times against lies.

If the investigator focuses on an unilateral scenario, the investigation cannot be objective and receives a feature with pretty severe consequences. A risk not very low, is represented by the indifference towards the fate of the person and his sufferance, indifference that leaves marks in the investigator's psychology. If, as a result of the long experience as an investigator, there emerge in the personality of the investigator certain features of indifference and severity, without him realizing this, he becomes carrier of the highly damaging and dangerous visions. Such a severity shall undoubtedly emerge in his practice, connected to the concrete case, reflecting in the quality of his investigation and work.

The investigator cannot accept, treat the good and the bad with indifference. He must be in the same time the enemy of the bad and the tireless warrior of the good, respecting with correctness the liberty and the essential rights of the person investigated.

The indifference of the investigator is associated sometimes with inadvertently and impatience. Each one of these negative qualities is extremely dangers for the investigation and must be avoided through the desire and sense of responsibility investigator has for his job.

A special place is occupied by the so-called excessive self-trust, related to the extremely firm conclusions, without a correct assessment of them. Encouraged by the successful demarche of the investigation due to the accuracy of his previous hypothesis, the investigator sometimes starts to believe very much in his intuition, proving an excessive selfconfidence and an interior belief, that "he is never wrong".

However, his inner belief, no matter how strong, cannot be considered evidence. Of course, this inner belief helps 
him in most of the cases to choose the right way, suggesting him the correct choice, creating an exact impression on the person, but he must not completely rely on them. The investigator must verify his inner belief with rigorously verified deeds, with objective circumstances, critically assessing them from all points of view. In other words, the investigator must maintain a cautious attitude, autocratic and demanding in all its impressions.

An important part in the investigator's psychology is played in the investigation of the witnesses and the defendants. In case of the defendant's investigation, the investigator must avoid prejudging the defendant, relying on the fact that he is defendant and he must never be trusted. Interrogating him with tenacity, the investigator must avoid the shameful methods such as: promises of any kind, moral influence etc.

The investigator must learn to listen patiently the objectives and arguments of the defendant, his reasons and references, fight in his mind with the extremely high feeling of anger and impatience and not express his personal feelings towards the defendant, performing his official duties with calm and decision.

\section{Investigator's Psychology in the Interrogation of the Witness}

During the interrogation of the witness, the investigator must take into consideration the fact that, for him, the investigation is not something he is used to, but for the witness is a serious thing, which sometimes causes a deep emotional impact he will remember for a long time.

Precisely for this reason, the investigator must be very careful and correct. The investigation of the witness must perform in a calm environment where the witness shows feelings of respect towards the investigator and towards the sense of responsibility of his statements. For example, the moment of procedure, consisting of the prior alert of the witness for the responsibility he has if the makes a false statement, can be used by the investigator in a tactic manner, alerting the witness in a serious and clear manner.

The constant calm during the investigation, attention, detailed investigation, deep objectivity showed by the investigator are elements which help creating a proper environment for the investigation and sent to the witness, the sense of responsibility towards his statements. In return, the impatience of the investigator, his superficiality, the formal approach of the questions, the desire to finish the work as soon as possible, obliging the witness to answer as fast as possible - "we jump over this, say it short and fast" etc - misleads the witness, arouse in him a state of nervousness and the belief of the lack of seriousness and the formal character of the questions.

A special importance, during the interrogation, has it the unconscious "suggestion" by the investigator of those details and circumstances he knows very well, but the witness doesn't. Sometimes, less experienced investigators, unwillingly, suggest the witness's details through words and those, due to the respect they have for the investigator, easily accept these suggestions (S. BEGEJA, $2005:$ p. 346). In the end, due to these things, the investigator draws the conclusions by himself through the witness investigated.

Sometimes, the investigator, unwillingly, during the investigation and on the occasion of filling the minute of the investigation, adds personal opinions to certain facts, circumstances, conclusions and evidence.

Still, there is no doubt that all the features of the personality and psychology of the investigator, general and professional culture, capacity to understand correctly the testimonies of the witnesses and of the defendant, the capacity to memorize and subsequently reproduce them in the minute of the investigation, influences the performance and result of the investigation, inevitably and in most of the cases, in an unconscious manner for the investigator.

\section{Self-Control of the Investigator in the Investigator's Psychology and his Role in the Performance of Completing the Investigation}

Given the above mentioned indicators, there emerges the need of the self-control of the investigator, being obliged to keep in mind the importance of the continuous improvement, of his sympathies and antipathies, excessive trust or exaggerated doubt, fighting along the investigation process against sorrow, anger" (Durmanov, 1967:p. 353)etc.

Besides these deeds, simply emotional, which influence the investigator's psychology, in his attitude towards the defendant and the case, another highly important element must be taken into consideration - the perception of the testimonies heard by him, of physical evidence brought, of documents revised by him and all circumstances of the case and the way he perceives the case, based on these elements. The problem resides in the fact that the points of view of the investigator are a result of a pure and simple creative process, where the investigator analyzes all the evidence collected by his habits, point of view, his experiences as investigator and his own assessment criteria. The problem resumes in this way, in the clarification of this process of creation, so that the "decision" accepted at the end of the trial, 
regarding the case, as the final conclusions of the investigator, be or not correct from the logic, objective and more accurate point of view.

The close connection with the so-called "law of judicial perspective" (Jaho., 1995), resides in the fact that many conclusions and assessments of the investigator regarding the case, suffer important changes along the trial, so, if based on the investigation is presented and assessed in a certain way, in certain cases it suddenly takes a different understanding and content. This thing results due to the incapacity of certain investigators, during the summary of the results of the investigation, asses as a whole, the evidence and conclusions in their potential, perspective and legal plan. The testimonies, which in the event of the investigation are performed at the premises of the investigator face to face and sound in a certain way, it sometimes happen that, during the crossed questioned addressed in front of the audience in the courtroom sound differently. In certain conditions, different from the ones of investigation, if the investigator did not consolidate in time the testimonies with relevant verifications and did not combine them with the other evidence of the case, then the testimonies of the witness or the defendant might lose their original meaning.

But, not only can the testimonies of the witnesses and the defendants sometimes suffer important changes in the trial. The conclusions of the investigation reflected in the accusations presented to the defendant of the accusations of the body of criminal procedure connected to the case, are submitted to a judicial investigation and assessment. In certain cases they do not pass this assessment. This thing, results because the investigator did not consider in time all the circumstances of the investigation, all hidden possibilities of the investigation, all scenarios taken into account during the trial, briefly, the investigator was not able to properly present the criminal perspective the case.

But the investigator must assist, as appropriate, in the court during the verification of the investigation. In this way, the investigator may discover the gaps of the investigation, the sufficient un-clarity of certain circumstances, sufficient depreciation of certain elements, testimonies, documents, references, arguments etc. It is important for young investigators to monitor the verification of their investigation to understand its gaps and to learn to improve his subsequent activity. The obligatoriness of the investigator resides in the fact that he must learn to anticipate this perspective, eliminating on time the gaps of the investigation, protecting himself from the possible uncontrolled movements and in some cases the challenges of the defendant, bringing to justice clear, correct and verified evidence.

In practice, before referring the case to the court in order to complete the investigation, all the pro and con arguments of the defendant must be analyzed again, mentioning the position of the defendant and the witnesses in court, the position of the defence, all unforeseen things that might occur, briefly, all circumstances connected to the verification and determination of the defendant's guilt, reasons, circumstances and consequences of the criminal act.

Before referring the case to the court, the investigator must visualize the case in his mind from different points of view and only after he is convinced that the conclusions are correct and supported to formulate the application for commencement of prosecutions. Autocratically considering his work and conclusions, the investigator makes sure that the unpleasant "surprises" that might occur, such as a court's decision to resend the case for additional completions. Only with an exacting attitude towards himself and his work, the investigator shall be entitled to fulfil his task, without leaving uncovered any offence and without allowing any case of criminal responsibility to be groundless.

No matter the type of offence and the person to whom it is attributed to, the investigator must treat with attention and care the start of criminal prosecutions and accusations brought, taking into consideration the high responsibility of his profession towards any case investigated by him and towards any person accused by him.

\section{Conclusions}

Self-control has a significant importance in the work of the investigator' who performs investigations for documenting criminal activities, for the control of incriminating conclusions, intuition, assumptions and scenarios proposed by him. Intuition, talent and professional tenacity and objectivity of the investigator are features that guide and help him in solving the case and finding out the truth.

The inner belief, no matter how strong, cannot be taken into consideration as evidence. This inner belief helps him in most cases, choose the right way, suggesting him the correct choice, forming him an exact impression on the human, but he must completely base on them. The investigator must verify his inner belief with rigorously verified deeds, with objective circumstances, critically assessing them from all points of view. In other words, the investigator must maintain an cautious, autocratic and demanding attitude of his impressions.

An important part in the investigator's psychology is played by the interrogation of the witness and defendants. In case of the investigation of the defendant, the investigator must avoid prejudging the defendant, based on the fact that he is a defendant and must never be trusted. Interrogating him with tenacity, the investigator must avoid the shameful 
methods such as: promises of any kind, moral influence etc.

During the interrogation of the witness, the investigator must take into consideration the fact that, for him, the investigation is not something he is used to, but for the witness is a serious thing, which sometimes causes a deep emotional impact he will remember for a long time.

Another highly important element must be taken into consideration - the perception of the testimonies heard by him, of physical evidence brought, of documents revised by him and all circumstances of the case and the way he perceives the case, based on these elements.

Experienced investigators must assist, as appropriate, in the court during the verification of the investigation. In this way, the investigator may discover the gaps of the investigation, the sufficient un-clarity of certain circumstances, sufficient depreciation of certain elements, testimonies, documents, references, arguments etc. It is important for young investigators to monitor the verification of their investigation to understand its gaps and to learn to improve his subsequent activity.

Before referring the case to the court, the investigator must visualize the case in his mind from different points of view and only after he is convinced that these conclusions are correct and supported to formulate the application for commencement of prosecutions. Autocratically considering his work and conclusions, the investigator makes sure that the unpleasant "surprises" that might occur, such as a court's decision to resend the case for additional completions. Only with an exacting attitude towards himself and his work, the investigator shall be entitled to fulfil his task, without leaving uncovered any offence and without allowing any case of criminal responsibility to be groundless.

\section{References}

Durmanov, N. (1967:p. 353). Mledhja, fiksimi dhe cmuarja e provave. Moscow: Moscow.

Jaho., N. (1995). "Mbi disa ceshjte te metodes se punes se prokurorise ne ushtrimin e funksionve te saj". Magazine "Drejtsia" , no. 3-4,. S. BEGEJA. (2005 : p. 346). Kriminalistika, . Tirana: Sugjestionimi.

Vishinski, A. ( 1956, p.348). - Manuali, Editia I, . Moske: Botini Prokurorisē së Përgjithshme. 
